\title{
Molecular Genetic Characteristics of Methicillin-Resistant Staphylococcus aureus Isolated from University Campus Environment and Students
}

\author{
Heechul Park ${ }^{1,2, \$, *}$, Sung-Bae Park ${ }^{1,2, \$, *}$, Junseong Kim ${ }^{1,2, *}$, Hyeonjeong Jeon ${ }^{1, * *}$, \\ Sein Choi ${ }^{1, * *}$, Seungyeon Lee ${ }^{1, * *}$, Eunchong $\mathrm{Oh}^{1, * *}$, Soenghwi Hwang ${ }^{1, * *}$, \\ Hyunjung Kim ${ }^{3, * * *}$, Jungho $\mathrm{Kim}^{1, ;, * * * *}$ and Sunghyun $\mathrm{Kim}^{1,2, ; * * * * *}$ \\ ${ }^{1}$ Department of Clinical Laboratory Science, College of Health Sciences, \\ Catholic University of Pusan, Busan 46252, Korea \\ ${ }^{2}$ Clinical Trial Specialist Program for In Vitro Diagnostics, Brain Busan 21 Plus Program, \\ the Graduate School, Catholic University of Pusan, Busan 46252, Korea \\ ${ }^{3}$ QuantaMatrix Inc., Seoul National University Hospital CMI, Jongno-gu, Seoul 03082, Korea
}

Staphylococcus aureus (S. aureus) is known as a bacterium that can cause skin infections, respiratory system infections, and sinusitis; however, it can exist as a normal flora rather than a pathogen. Recently, methicillin-resistant $S$. aureus (MRSA) infections have emerged in the community as a new variant of community-associated (CA)-MRSA. In the present study, S. aureus and MRSA were isolated and cultured by collecting samples from facilities and environments where students and educational personnel have multiple contacts on university campuses; specifically, the nostrils and hands of college students were tested from July to September of 2019. The molecular properties of the isolated MRSA were analyzed, and the one MRSA strain was isolated from the university campuses. One MRSA that was isolated and cultured on campus was the mec complex group A and staphylococcal cassette chromosome (SCC) mec type II, which is a characteristic of healthcare-associated (HA)-MRSA, and SCCmec type V, which is a characteristic of CA-MRSA. This result was similar to other studies wherein the SCCmec type II was detected in SCCmec typing analysis in CAMRSA. To confirm whether there is a new variant of CA-MRSA in the Republic of Korea, additional follow-up studies on the analysis of virulence factors of MRSA are needed by additionally separating CA-MRSA from the body parts of university students and educational personnel.

Key Words: Staphylococcus aureus, Methicillin-resistant Staphylococcus aureus (MRSA), Community associated-MRSA (CA-MRSA), Frequency of Staphylococcus spp.

\footnotetext{
Received: May 20, 2020 / Revised: July 28, 2020 / Accepted: August 18, 2020

* Graduate student, ${ }^{* *}$ Undergraduate student, ${ }^{* * *}$ Researcher, ${ }^{* * * *}$ Professor.

$\S^{\S}$ These authors have contributed equally.

${ }^{\dagger}$ Corresponding author: Jungho Kim. Department of Clinical Laboratory Science, College of Health Sciences, Catholic University of Pusan, Busan 46252, Korea.

Tel: +82-51-510-0660, Fax:+82-51-510-0568, e-mail: jutosa70@cup.ac.kr

${ }^{\dagger}$ Corresponding author: Sunghyun Kim. Department of Clinical Laboratory Science, College of Health Sciences, Catholic University of Pusan, Busan 46252, Korea.

Tel: +82-51-510-0560, Fax:+82-51-510-0568, e-mail: shkim0423@cup.ac.kr

(C) The Korean Society for Biomedical Laboratory Sciences. All rights reserved.

(c) This is an Open Access article distributed under the terms of the Creative Commons Attribution Non-Commercial License (http://creativecommons.org/licenses/by-nc/3.0/) which permits unrestricted non-commercial use, distribution, and reproduction in any medium, provided the original work is properly cited.
} 
그람 양성 포도알균의 한 종인 황색포도알균(Staphylococcus aureus)은 코, 호흡기계통, 피부에 존재하며 피부 감염이나 호흡기계 감염, 부비강염, 식중독 등을 일으킬 수 있으나 병원체가 아닌 정상 세균총(Normal flora)으로 존재할 수 있는 균으로 알려져 있다(Miller and Diep, 2008; Ostojić and Hukić, 2015). S. aureus 감염증으로 인한 사망률 은 1940 년 이전에 항생제가 사용되기 전에는 $90 \%$ 에 달 하였지만, penicillin을 이용한 항생제가 도입이 되면서 사 망률은 급격히 떨어 졌다(Suginaka et al., 1979). 하지만 penicillin을 사용한지 10년만에 S. aureus은 penicillin에 내 성을 가졌고, 그 이후에 S. aureus가 분비하는 베타락탐 분해효소에도 분해되지 않는 항생제인 methicillin이 개 발되어 사용되었지만 곧 methicillin에도 내성을 가지는 methicillin-resistant S. aureus (MRSA)가 출현하였다(Crosby et al., 2016). 이러한 MRSA의 내성 기전은 세균이 선천적 으로 염색체 내에 methicillin resistant determinant $\mathrm{A}(\mathrm{mec} \mathrm{A})$ 유전자를 획득하여 약제에 친화성이 적은 penicillin binding protein $2 \mathrm{a}(\mathrm{PBP} 2 \mathrm{a})$ 에 의하여 생기는 것으로 알려져 있다. 따라서, mecA 유전자를 보유한 균주는 penicillin, cephalosporin, carabapenem, monobactam 등 거의 모든 $\beta$-lactam 제 제에 내성을 나타내게 된다(Lakhundi and Zhang, 2018).

S. aureus에 대한 국내에서의 methicillin 내성률은 최 근 수십 년 동안 계속해서 증가해왔으며, 현재 MRSA는 한국의 3차 의료기관에 있는 모든 S. aureus 분리 균주의 $60 \sim 70 \%$ 를 차지한다고 보고되고 있다(Kang et al., 2016). 이와 같은 MRSA 균주는 항생제에 다제 내성을 나타내어 병원 내 감염의 주요 원인균으로 전 세계적으로 문제시 되고 있다. MRSA 균주의 역학 그룹을 구별하기 위해 의 료기관관련 MRSA (hospital-associated MRSA, HA-MRSA) 와 지역사회관련 MRSA (community-associated MRSA, CAMRSA)로 구분하고 있다(Petinaki and Spiliopoulou, 2012). 1980년대 초 미국에서 MRSA 감염의 위험인자가 없는 건 강한 지역사회 거주자에게 MRSA 감염이 유행하면서 CAMRSA 감염이 알려지면서 그에 따른 위험성이 많이 보고 되고 있다(Jung and Kim, 2015). CA-MRSA의 감염증은 HA-MRSA 감염증에 비해 피부나 연조직 감염증이 더 흔 히 유발하고, 감염되는 대상자의 연령도 낮으며, $\beta$-lactam 계 항생제를 제외한 ciprofloxacin, clindamycin, gentamicin, trimethoprim-sulfamethoxazole 등의 항생제에도 감수성을 보이는 경우가 많기 때문에 CA-MRSA의 분자유전학적 특성 분석을 통한 역학적 연구가 필요한 상황이다(Sowash and Uhlemann, 2014).
이러한 MRSA의 중요성에도 불구하고 국내에서의 환 경 유래 MRSA의 연구가 미흡한 실정이다. 따라서 본 연 구에서는 대학 캠퍼스 내 학생 및 교직원이 접촉이 많은 시설 및 환경 그리고 대학생의 특정 신체 부위(콧구멍, 손)로부터 표본을 수집하여 S. aureus 를 분리 배양하고 그 분포를 조사하여, $\mathrm{MRSA}$ 의 감별 및 분리된 $\mathrm{MRSA}$ 의 분자유전학적 특성을 분석하고자 하였다.

2019년 7월부터 9월까지 부산가톨릭대학교 캠퍼스 내 학생 및 교직원들의 출입이 많은 3 개의 건물(건물 $\mathrm{A}, \mathrm{B}$, $\mathrm{C}$ )에서 사람들의 접촉이 많은 환경(출입문 손잡이, 창문, 책상, 키보드, 에어컨, 정수기, 엘리베이터 버튼 등)과 대 학생의 손, 비강으로부터 멸균 면봉을 이용해 가검물을 수집하였다.

수집한 가검물을 영양 - 증균배지인 Nutrient agar (Kisan$\mathrm{Bio}$, Seoul, Korea)에 접종하여 $37^{\circ} \mathrm{C}$ 세균 배양기에서 16 24시간 1차 배양하였다. 1차 배양 후, 배지에서 자란 모든 집락 수를 세고, 형성된 세균의 집락 모양, 색을 관찰하 여 여러 종의 미생물이 복합적으로 집락을 형성한 경우, 단일 집락으로 분리하기 위해 Nutrient agar에 2차 계대 배 양하였다. 1차 또는 2차 계대 배양을 통하여 얻어진 단일 집락을 세균 동정 검사와 내성 유전자 검사에 이용하였다.

단일 집락으로 분리된 세균의 동정을 위하여 Gram 염 색을 실시하였다. Gram 염색의 염색상을 바탕으로 Gram 양성 알균을 일차적으로 구분하였다. 확인된 Gram 양성 알균은 S. aureus 분리를 위한 선택배지인 Mannitol Salt Agar (MSA) 평판배지(KisanBio, Seoul, Korea)에 접종하여 $37^{\circ} \mathrm{C}$ 세균 배양기에서 16 24시간 배양하였다. MSA 배지 에서 mannitol 분해능 양성을 나타내는 균은 S. aureus로 동정한 후, S. aureus-specific PCR로 확인동정 하였다. 한편, Mannitol 분해능 음성을 나타내는 Gram 양성 알균의 종 확인 동정은 세균 $16 \mathrm{~S} \mathrm{rRNA}$ 염기서열분석법을 이용하 였다.

종(Species) 수준까지의 세균 동정을 위한 염기서열분석 법 및 MRSA의 분자유전학적 특성 분석을 위하여 분리 된 단일 집락으로부터 Genomic DNA (gDNA) 추출하였다. 배지에서 배양된 세균의 단일 집락을 백금이로 취한 후 $5 \%$ Chelex ${ }^{\circledR}$ Resin (Bio-Rad, Hercules, CA, USA)/TBE 용액 $500 \mu \mathrm{L}$ 에 혼탁 시킨 후 $90 \sim 95^{\circ} \mathrm{C}$ 에서 10 분간 끓인 후 $3,000 \times \mathrm{g}$ 로 10 분간 원심분리한 상층액을 멸균 튜브에 옮 긴 후 분석 시까지 $-20^{\circ} \mathrm{C}$ 에서 냉동 보관하였다.

선택배지인 MSA에서 양성을 나타낸 균들의 단일 집락 을 이용하여 S. aureus-specific PCR과 MRSA (mecA)-specific 
PCR을 수행하기 위해 Prime Taq PCR Premix (GeNet Bio, Daejeon, Korea) $10 \mu \mathrm{L}$ 와 Forward 및 Reverse primer를 각 각 $10 \mathrm{pmol}$, 추출한 $\mathrm{gDNA}$ 를 주형 $\mathrm{DNA}$ 로 $3 \mu \mathrm{L}$, 멸균증류 수 $5 \mu \mathrm{L}$ 를 첨가하여 총 $20 \mu \mathrm{L}$ 의 혼합액을 만들어 $\mathrm{PCR}$ 을 수행하였다. 본 연구에 사용된 primer의 염기서열은 기존 연구자료를 바탕으로 시행하였다(Table 1). S. aureus-specific $\mathrm{PCR}$ 의 조건은 $94^{\circ} \mathrm{C}$ 에서 5 분간 pre-denaturation 과정 후 denaturation 과정 $94^{\circ} \mathrm{C}$ 에서 30 초, primer annealing 과정 $60^{\circ} \mathrm{C}$ 에서 30 초, extension 과정 $72^{\circ} \mathrm{C}$ 에서 30 초 과정으로 30 cycle 반복하고 final extension 과정 $72^{\circ} \mathrm{C} 5$ 분 반응하였 다. MRSA (mecA)-specific PCR의 조건은 $94^{\circ} \mathrm{C}$ 에서 5 분간 pre-denaturation 과정 후 denaturation 과정 $94^{\circ} \mathrm{C}$ 에서 30초, primer annealing 과정 $50^{\circ} \mathrm{C}$ 에서 30 초, extension 과정 $72^{\circ} \mathrm{C}$ 에서 30 초 과정으로 40 cycle 반복하고 final extension 과정 $72^{\circ} \mathrm{C} 10$ 분 반응하였다. 증폭 반응이 끝난 $\mathrm{PCR}$ 산물은
$2 \%$ agarose/TBE gel DNA 전기영동을 통해 그 결과를 확인 하였다. 추가적으로 MSA 배양 결과 양성을 나타냈지만, S. aureus-specific PCR 결과 음성으로 나타난 단일 집락 을 대상으로 Bacterial 16S rRNA sequencing 분석을 진행 하였다.

분리 배양된 MRSA의 분자유전학적 특성 비교를 위해 $\mathrm{SCCmec}$ 과 mec complex typing을 수행하였고, Prime Taq PCR Premix $10 \mu \mathrm{L}$ 와 Forward 및 Reverse primer를 각각 10 $\mathrm{pmol}$, 추출한 $\mathrm{gDNA}$ 를 주형 $\mathrm{DNA}$ 로 $3 \mu \mathrm{L}$, 멸균증류수 $5 \mu \mathrm{L}$ 를 첨가하여 총 $20 \mu \mathrm{L}$ 의 혼합액을 만들어 분석하였다. 본 연구에 사용된 primer의 염기서열은 기존 연구자료를 자료를 바탕으로 시행하였다(Table 1).

$\mathrm{SCC} m e c$ subtyping $\mathrm{PCR}$ 의 조건은 $94^{\circ} \mathrm{C}$ 에서 5 분간 pre-denaturation 과정 후 denaturation 과정 $94^{\circ} \mathrm{C}$ 에서 30초, primer annealing 과정 $55^{\circ} \mathrm{C}$ 에서 30 초, extension 과정 $72^{\circ} \mathrm{C}$

Table 1. Specific primer sets used in this study for subtyping of SCCmec type \& mec complex subtypes in methicillin-resistant Staphylococcus aureus environmental isolates

\begin{tabular}{|c|c|c|c|c|}
\hline Target region & & Nucleotide sequence (5'-3') & Amplicon size (bp) & References \\
\hline \multirow{2}{*}{ S.aureus-specific PCR } & $\mathrm{F}$ & 5'-GCG ATT GAT GGT GAT ACG GTT-3' & \multirow{2}{*}{267} & \multirow{2}{*}{$\begin{array}{c}\text { Brakstad et al., } \\
1992\end{array}$} \\
\hline & $\mathrm{R}$ & 5'-AGC CAA GCC TTG ACG AAC TAAAGC-3' & & \\
\hline \multirow{2}{*}{ SCCmec type I } & $\mathrm{F}$ & 5'-GCT TTAAAG AGT GTC GTT ACA GG-3' & \multirow{2}{*}{613} & \multirow{22}{*}{ Kim et al., 2018} \\
\hline & $\mathrm{R}$ & 5'-GTT CTC TCA TAG TAT GAC GTC C-3' & & \\
\hline \multirow{2}{*}{ SCCmec type II } & $\mathrm{F}$ & 5'-CGT TGA AGA TGA TGA AGC G-3' & \multirow{2}{*}{398} & \\
\hline & $\mathrm{R}$ & 5'-CGAAAT CAA TGG TTAATG GAC C-3' & & \\
\hline \multirow{2}{*}{ SCCmec type III } & $\mathrm{F}$ & 5'-CCA TAT TGT GTA CGA TGC G-3' & \multirow{2}{*}{280} & \\
\hline & $\mathrm{R}$ & 5'-CCT TAG TTG TCG TAA CAG ATC G-3' & & \\
\hline \multirow{2}{*}{ SCCmec type IVa } & $\mathrm{F}$ & 5'-GCC TTA TTC GAA GAA ACC G-3' & \multirow{2}{*}{776} & \\
\hline & $\mathrm{R}$ & 5'-CTA CTC TTC TGAAAA GCG TCG-3' & & \\
\hline \multirow{2}{*}{ SCCmec type IVb } & $\mathrm{F}$ & 5'-TCT GGA ATT ACT TCA GCT GC-3' & \multirow{2}{*}{493} & \\
\hline & $\mathrm{R}$ & 5'-AAA CAA TAT TGC TCT CCC TC-3' & & \\
\hline \multirow{2}{*}{ SCCmec type IVc } & $\mathrm{F}$ & 5'-ACA ATA TTT GTA TTA TCG GAG AGC-3' & \multirow{2}{*}{200} & \\
\hline & $\mathrm{R}$ & 5'-TTG GTA TGA GGT ATT GCT GG-3' & & \\
\hline \multirow{2}{*}{ SCCmec type IVd } & $\mathrm{F}$ & 5'-CTC AAA ATA CGG ACC CCA ATA CA-3' & \multirow{2}{*}{881} & \\
\hline & $\mathrm{R}$ & 5'-TGC TCC AGT AAT TGC TAA AG-3' & & \\
\hline \multirow{2}{*}{ SCCmec type V } & $\mathrm{F}$ & 5'-GAA CAT TGT TAC TTAAAT GAG CG-3' & \multirow{2}{*}{325} & \\
\hline & $\mathrm{R}$ & 5'-TGAAAG TTG TAC CCT TGA CAC C-3' & & \\
\hline \multirow{2}{*}{ mecA } & $\mathrm{F}$ & 5'-GTG AAG ATA TAC CAA GTG ATT-3' & \multirow{2}{*}{147} & \\
\hline & $\mathrm{R}$ & 5'-ATG CGC TAT AGA TTG AAA GGA T-3' & & \\
\hline \multirow{2}{*}{ mec complex group A } & $\mathrm{F}$ & 5'-CCC TTT TTA TAC AAT CTC GTT-3' & \multirow{2}{*}{146} & \\
\hline & $\mathrm{R}$ & 5'-ATA TCA TCT GCA GAA TGG G-3' & & \\
\hline \multirow{2}{*}{ mec complex group B } & $\mathrm{F}$ & 5'-TAT TTT TGG GTT TCA CTC GG-3' & \multirow{2}{*}{1,305} & \\
\hline & $\mathrm{R}$ & 5'-CTC CAC GTT AAT TCC ATT AAT ACC-3' & & \\
\hline
\end{tabular}


에서 30초 과정으로 40 cycle 반복하고 final extension 과 정 $72^{\circ} \mathrm{C} 10$ 분 반응하였다. MRSA IVb typing PCR의 조건 은 $94^{\circ} \mathrm{C}$ 에서 5 분간 pre-denaturation 과정 후 denaturation 과정 $94^{\circ} \mathrm{C}$ 에서 30 초, primer annealing 과정 $50^{\circ} \mathrm{C}$ 에서 30 초, extension 과정 $72^{\circ} \mathrm{C}$ 에서 1 분 과정으로 $35 \mathrm{cycle}$ 반복하고 final extension 과정 $72{ }^{\circ} \mathrm{C} 10$ 분 반응하였다. mec complex A, $\mathrm{B}$ typing $\mathrm{PCR}$ 의 조건은 $94^{\circ} \mathrm{C}$ 에서 5 분간 pre-denaturation 과정 후 denaturation 과정 $94^{\circ} \mathrm{C}$ 에서 30 초, primer annealing 과정 $54^{\circ} \mathrm{C}$ 에서 30 초, extension 과정 $72^{\circ} \mathrm{C}$ 에서 1 분 과정으 로 35 cycle 반복하고 final extension 과정 $72^{\circ} \mathrm{C} 10$ 분 반응 하였다. 증폭 반응이 끝난 $\mathrm{PCR}$ 산물은 $2 \%$ agarose/TBE gel DNA 전기영동을 통해 그 결과를 확인하였다.
수집한 총 150 개의 가검물 모두에서 균집락이 관찰되 었으며 단일 집락 407 개를 분리하였다. 분리된 균의 결 과는, Gram-양성 세균 중에서 Gram-양성 알균이 226건 (55.5\%), Gram-양성 막대균이 58건(14.3\%), Gram-음성 알균 이 40건(9.8\%), Gram-음성 막대균이 70 건(17.2\%), 사상형 진균이 13 건(3.2\%)으로 확인되었다(Table 2). Gram-양성 알 균을 제외한 Gram-양성 막대균, Gram-음성 알균, Gram-음 성 막대균은 일반적인 환경 내 오염균으로 추정이 되며, fungi 13 건(3.2\%)는 사상형 진균으로 환경 내 존재하는 진 균이였다.

Gram 염색에서 Gram 양성 알균으로 확인된 총 226개 의 단일 집락을 대상으로 $S$. aureus의 선택배지인 MSA에

Table 2. Distribution of environmental strains

\begin{tabular}{lcccccc}
\hline \hline & $\begin{array}{c}\text { Gram-positive } \\
\text { cocci }\end{array}$ & $\begin{array}{c}\text { Gram-positive } \\
\text { bacilli }\end{array}$ & $\begin{array}{c}\text { Gram-negative } \\
\text { cocci }\end{array}$ & $\begin{array}{c}\text { Gram-negative } \\
\text { bacilli }\end{array}$ & $\begin{array}{c}\text { Filamentous } \\
\text { fungi }\end{array}$ & $\begin{array}{c}\text { Total } \\
\text { n, }(\%)\end{array}$ \\
\hline Building A & $74(50.3)$ & $15(10.2)$ & $9(6.1)$ & $41(27.9)$ & $8(5.4)$ & $147(36.1)$ \\
Building B & $69(55.2)$ & $21(16.8)$ & $15(12.0)$ & $18(14.4)$ & $2(1.6)$ & $125(30.7)$ \\
Building C & $70(59.3)$ & $21(17.8)$ & $14(11.9)$ & $10(8.5)$ & $3(2.5)$ & $118(29.0)$ \\
Body & $13(76.5)$ & $1(5.9)$ & $2(11.8)$ & $1(5.9)$ & $0(0.0)$ & $17(4.2)$ \\
\hline Total & $226(55.5)$ & $58(14.3)$ & $40(9.8)$ & $70(17.2)$ & $13(3.2)$ & $407(100.0)$ \\
\hline
\end{tabular}

Table 3. Identification of MSA positive strains through bacterial 16S rRNA sequencing analysis

\begin{tabular}{llllc}
\hline \hline & \multicolumn{1}{c}{ Species } & \multicolumn{1}{c}{ Identity (range) } & Accession & n. (\%) \\
\hline & Staphylococcus caprae & $99.94 \%(99.76 \sim 100)$ & MT225637.1 & $22(25.9)$ \\
& Staphylococcus saprophyticus & $99.96 \%(99.81 \sim 100)$ & MN135302.1 & $8(9.4)$ \\
& Staphylococcus hominis & $99.86 \%(99.2 \sim 100)$ & CP050982.1 & $6(7.1)$ \\
& Staphylococcus cohnii & $99.96 \%(99.9 \sim 100)$ & MT225636.1 & $6(7.1)$ \\
& Staphylococcus haemolyticus & $99.98 \%(99.9 \sim 100)$ & MN535877.1 & $6(7.1)$ \\
Staphylococcus spp. & Staphylococcus edaphicus & $99.96 \%(99.89 \sim 100)$ & MT256060.1 & $5(5.9)$ \\
& Staphylococcus warneri & $99.92 \%(99.82 \sim 100)$ & MN220585.1 & $5(5.9)$ \\
& Staphylococcus epidermidis & $99.98 \%(99.81 \sim 100)$ & MN889374.1 & $4(4.7)$ \\
& Staphylococcus pasteuri & $99.7 \%(99.61 \sim 99.8)$ & CP017463.1 & $2(2.4)$ \\
& Staphylococcus sciuri & $100 \%$ & KY316479.1 & $1(1.2)$ \\
& Staphylococcus capitis & $100 \%$ & MH127801.1 & $1(1.2)$ \\
\hline Micrococcus spp. & $100 \%(100 \sim 100)$ & MT254789.1 & $5(5.9)$ \\
\hline Others & Kocuria rhizophila & $99.69 \%(99.36 \sim 100)$ & KC429605.1 & $3(3.6)$ \\
& Stenotrophomonas maltophilia & $100 \%$ & MT199170.1 & $1(1.2)$ \\
& Microbacterium laevaniformans & $100 \%$ & MT279967.1 & $1(1.2)$ \\
\hline Total confirmed & Enterobacter spp. & $100 \%$ & MT270807.1 & $1(1.2)$ \\
\hline
\end{tabular}


Table 4. Results of S. aureus-specific and MRSA-specific PCR

\begin{tabular}{|c|c|c|c|c|}
\hline PCR & \multicolumn{2}{|c|}{ Positive, n (\%) } & Negative, $\mathrm{n}(\%)$ & Total, n (\%) \\
\hline S. aureus-specific PCR & \multicolumn{2}{|c|}{$4(4.5)$} & \multirow{3}{*}{$85(95.5)$} & \multirow{3}{*}{$89(100.0)$} \\
\hline \multirow{2}{*}{ MRSA-specific PCR } & Positive & Negative & & \\
\hline & 1 & 3 & & \\
\hline
\end{tabular}

Table 5. Genetic properties of CA-MRSA isolated from campus environmental strains detected in this study

\begin{tabular}{|c|c|c|c|c|c|c|c|c|c|c|c|c|}
\hline & \multirow{2}{*}{$\begin{array}{c}\text { MRSA } \\
m e c \mathrm{~A}\end{array}$} & \multicolumn{2}{|c|}{ mec Complex Types } & \multicolumn{8}{|c|}{ SCCmec types } & \multirow{2}{*}{ Genotypes } \\
\hline & & Group A & Group B & I & II & III & IVa & $\mathrm{IVb}$ & IVc & IVd & $\mathrm{V}$ & \\
\hline$\overline{\text { CA-MRSA }}$ & + & + & - & - & + & - & - & - & - & - & + & Group A, II, V \\
\hline
\end{tabular}

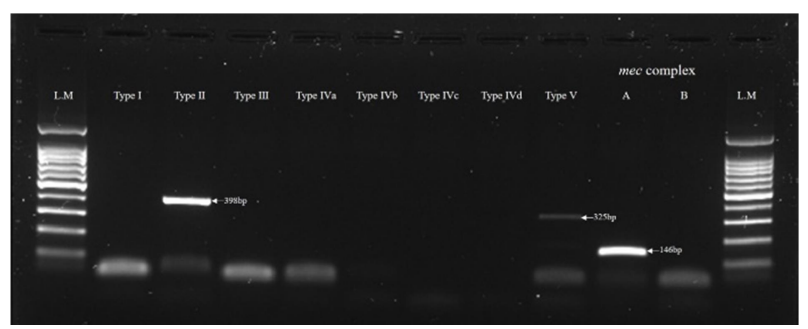

Fig. 1. Multiplex PCR assay to identify SCCmec subtypes and mec complex types. Multiplex PCR assay identifies SCCmec subtypes I (613 bp), II (398 bp), III (280 bp), IVa (776 bp), IVb (493 bp), IVc (200 bp), IVd (881 bp), V (325 bp) and mec complex A (146 bp), mec complex B (1,305 bp). L.M: Ladder marker

서 배양한 결과 Gram 양성 알균 중 89개(39.4\%)의 단일 집락에서 MSA 배양 양성이 확인되었다(Table 2). MSA 배 양 결과 양성을 나타낸 총 89 개의 단일 집락에 대하여 $S$. aureus-specific PCR을 수행한 결과 4개의 단일 집락에서 S. aureus으로 동정되었다. 한편, MSA 배양 결과 양성을 나타냈지만, S. aureus-specific PCR 결과 음성으로 나타난 85 개의 단일 집락을 대상으로 $16 \mathrm{~S} \mathrm{rRNA}$ 염기서열분석법 을 통한 동정 결과, S. aureus가 아닌 Staphylococcus species 가 66건, Micrococcus species가 5건, 기타 6건, 동정되지 않 은 균이 7건임을 확인하였다. Staphylococcus species 중 가 장 많이 분리된 균은 Staphylococcus capare(22건, 25.9\%) 이었으며, 모두 coagulase negative staphylococci (CONS)이 었다(Table 3).

MSA 배양 양성을 나타내며 S. aureus로 동정된 4개의 단일 집락에 대해 Methicillin 내성 관련 유전자인 $m e c \mathrm{~A}$ 유전자를 검출하기 위하여 MRSA (mecA)-specific PCR을 수행한 결과 1 개의 단일 집락에서 $m e c \mathrm{~A}$ 유전자를 가지고
있음을 확인하였다(Table 4).

MRSA (mecA)-specific PCR 결과 양성을 나타낸 1건을 이용하여 SCCmec typing과 mec complex typing을 수행한 결과 캠퍼스 환경에서 분리된 MRSA 균주는 SCCmec type II와 V임을 확인하였으며, mec complex type A임을 확인하 였다(Fig. 1, Table 5).

S. aureus는 자연계에 널리 분포하는 병원성 세균으로 사람의 피부에도 존재하고 병원성을 나타내지 않는 것도 있다. 병원성 S. aureus는 아포가 없는 균 중에서 저항성이 강한 부류에 속하며 건강한 피부는 통과하지 못하지만 다 양한 감염경로를 통하여 심각한 감염증을 일으킨다(Xie et al., 2016). 특히, 각종 시술 후 감염 및 각종 합병증으로 인한 중요 장기로의 침범은 생명을 위협하는 존재이다. $m e c \mathrm{~A}$ 유전자의 획득에 의해 내성을 획득한다고 알려져 있는 MRSA는 다양한 항생제에 내성을 나타내며, 병원 내 감염에서 가장 중요하다고 알려져 있으나, 최근에는 CA-MRSA 감염도 급격히 증가하고 있는 추세이다(Hong and Baek, 2017).

2014년 수행된 미국 중서부 지역에서의 MRSA 분포 양 상 분석 연구 결과에 따르면, 2004년과 2005년에 미국 중 서부 내 전체 MRSA 감염증 중 $63.5 \%$ 이 HA-MRSA 감염 증의 수치로 CA-MRSA 감염증 발생 비율보다 높았지만, 2008년에는 그 수치가 역전되어 CA-MRSA의 발생비율이 62.2\%로 더 높게 나타났다(David et al., 2014). HA-MRSA 감염증은 균혈증이나 폐렴 등 다양한 감염증의 원인이 되 는 것에 비해 CA-MRSA 감염증에서는 피부나 연조직 감 염증을 흔히 유발하는 것으로 보고되고, 환자들의 연령이 더 낮았으며, 사회 경제적 상태에 따른 발생 차이를 많이 보였다(Jung and Kim, 2015). 또한, 2012년 국내에서 보고된 
자료에 의하면, $S$. aureus 가 분리된 1,627명 중 CA-MRSA 가 102 명(13.0\%), HA-MRSA가 253명(32.2\%)로 확인되었다 (Kim et al., 2014). 특히, 최근에는 CA-MRSA 감염으로 인 한 사망사례가 보고됨에 따라 국내에서의 CA-MRSA에 대한 관심이 높아지고 있는 상황이다.

2019년 캐나다 앨버타주에서 수행된 한 연구 결과에 따르면, 3 년 동안 MRSA 감염증 중 CA-MRSA의 비율이 꾸준히 증가하였고, HA-MRSA $(38.5 \%)$ 에 비해 더 높은 비율(52.5\%)로 검출되었다고 보고되었다(Gill et al., 2019). 2014년 조지아 주의 미육군의 훈련 기지인 포트 베닝에 서 수행한 연구 결과에 따르면, 기초 군사훈련 동안 병사 $10 \%$ 에게서 MRSA 감염이 밝혀졌으며, 추가적인 연간 조 사 결과 1,000 명 중 42 명(약 $4.2 \%$ )이 MRSA 감염이 있는 것으로 보고되었다(Leamer et al., 2013).

최근, CA-MRSA 감염증은 과거에 비해 현저히 높은 양 상을 보이고 있고, MRSA가 의료기관 내원 환자가 아닌 지역사회에서도 분리 비율이 높은 것으로 봤을 때, 대학 교 및 직장 등 집단생활을 하는 사람들로부터 MRSA 감 염과 전파를 사전에 예방하는 것이 무엇보다도 중요하다 고 할 수 있으며, 이들로부터 MRSA 분리 비율을 조사하 고 분자유전학적 특성을 비교하는 조사는 큰 의미가 있다 고 볼 수 있다.

본 연구에서는 일차적으로, 대학 캠퍼스 내 생활 중인 대학생 및 교직원의 직접적인 접촉이 많은 다양한 시설 및 환경과, S. aureus 분리 비율이 가장 높은 대학생의 특 정 신체 부위로부터 수집한 가검물을 대상으로 S. aureus 와 $\mathrm{MRSA}$ 의 분리 빈도를 검사한 결과, MSA에서 분리 배 양된 89 개의 단일 집락 중 S. aureus가 4건(4.5\%), 그 중 MRSA가 1건(1.1\%)으로 확인되었다. 본 연구에서 검출된 $\mathrm{MRSA}$ 는 비록 1건이지만 유동인구가 많은 캠퍼스 환경 에서 분리되었다는 점은 최근 CA-MRSA의 감염 문제가 대두되고 있는 상황에서 간과할 수 없는 결과라고 사료 된다.

한편, MSA에서 분리 배양되어 종 수준까지 동정 된 Staphylococcus 속의 분리 비율을 살펴보면, Staphylococcus caprae(22건, 25.9\%), Staphylococcus saprophyticus(8건, 9.4\%) 의 순이었다. 이는 임상검체에서 분리되는 Staphylococcus 속 중 S. epidermidis의 분리 비율이 가장 높다는 이전 연 구 결과와는 차이가 있지만(Shin and Park, 2007), 검체 대 상 및 연구 목적의 차이로 생각이 된다. 균종 분리 비율이 다르긴 하지만, 전체 85 개의 분리균 중에서 66 (77.6\%)개 의 분리균이 Coagulase negative staphylcossus (CoNS)으로
매우 높은 비율을 차지했다는 것은 다른 국내 및 해외의 보고들과 유사한 결과로 확인이 되었으며, 이전에는 오염 균으로 간주되었으나, 최근 중요한 기회 감염균으로 대두 되고 있다는 점에서 후속연구를 통한 지속적인 조사가 필요할 것으로 사료된다.

CA-MRSA는 HA-MRSA와는 다른 유전자 및 표현형 특 성을 가지고 있다고 알려져 있는데, 현재 밝혀진 SCCmec type은 5종으로 mecA 유전자 복합체와 chromosomal cassettes recombinase $(\mathrm{ccr})$ 유전자 복합체의 조합에 따라 I 에서 V type이다[Kaszanyizky et al]. SCCmec type에 따라 HA-MRSA 및 CA-MRSA 균주의 상관관계에 대한 특성이 밝혀지고 있는데, 일반적으로 HA-MRSA는 SCCmec I, II 및 III에 속하며, CA-MRSA는 SCCmec IV 또는 V에 속한 다고 보고되어 진다(Peng et al., 2018).

캠퍼스에서 분리 배양된 1주의 MRSA는 mec complex group $\mathrm{A}$ 이면서 HA-MRSA에서 주로 나타나는 $\mathrm{SCCmec}$ type II와 CA-MRSA의 특징인 SCCmec type $\mathrm{V}$ 가 동시에 나타나는 것을 확인하였다. 이 결과는 CA-MRSA에서도 SCCmec type II가 나타날 수 있으며(Hisata et al., 2011), 지 역과 인종에 따라 $\mathrm{MRSA}$ 의 $\mathrm{SCCmec}$ type의 차이가 있다 는 연구 결과와 유사한 양상을 나타내고 있다(Funaki et al., 2019).

본 연구에서는 단기간에 대학 캠퍼스로부터 분리 배양 된 한 개의 CA-MRSA 균주로만 연구가 진행되었다는 한 계점이 있었기 때문에 전체 CA-MRSA의 분자유전학적 특성을 분석하기에는 통계적 유의성이 낮을 수 있다. 하 지만, 본 연구에서는 HA-MRSA에서 주로 나타나는 것으 로 알려진 SCCmec type II가 CA-MRSA에서 확인되었기 때문에 최근 CA-MRSA의 새로운 변종이 있을 수 있다는 가능성을 확인할 수 있었으며, 지역과 인종에 따라 CA$\mathrm{MRSA}$ 의 SCCmec type이 다를 수 있기 때문에 그 기준에 따른 MRSA 감염 예방을 위한 소독제 및 살균제 개발을 위한 기초자료로 활용될 수 있을 것이라고 사료된다.

대학 캠퍼스 환경 및 대학생들의 신체 부위에서 $S$. aureus 및 MRSA가 검출된 것으로 봤을 때 유동인구가 많은 곳에서의 $\mathrm{MRSA}$ 의 분리 배양과 감염을 예방할 수 있는 방법을 강구하는 것이 매우 중요할 것으로 판단된 다. 추가적으로 대학 캠퍼스 환경 외에 대학생과 교직원 의 신체 부위로부터 장기간에 걸쳐 S. aureus와 CA-MRSA 를 추가적으로 확보하여 본 연구를 통해 분리된 4 개의 $S$. aureus와 1 개의 MRSA, 그리고 다른 지역에서 분리된 CA$\mathrm{MRSA}$ 의 병원성 인자 분석에 관한 후속연구를 진행한다 
면, CA-MRSA의 새로운 변종의 발견과 효과적인 MRSA 감염 예방과 치료를 할 수 있을 것으로 사료된다.

\section{ACKNOWLEDGEMENT}

This work was supported by the Korea Foundation for the Advancement of Science \& Creativity (KOFAC), and funded by the Korean Government (Kofac 20198892457).

\section{CONFLICT OF INTEREST}

The researcher claims no conflicts of interest.

\section{REFERENCES}

Brakstad OG, Aasbakk K, Maeland JA. Detection of Staphylococcus aureus by Polymerase Chain reaction Amplification of the nuc Gene. Journal of Clinical Microbiology. 1992. 30: 1654 -1660 .

Crosby HA, Kwiecinski J, Horswill AR. Staphylococcus aureus aggregation and coagulation mechanisms, and their function in host-pathogen interactions. In: Advances in applied microbiology. Academic Press. 2016. 1-41.

David MZ, Cadilla A, Boyle-Vavra S, Daum RS. Replacement of HA-MRSA by CA-MRSA infections at an academic medical center in the midwestern United States, 2004-5 to 2008. PLoS One. 2014. 9: e92765.

Funaki T, Yasuhara T, Kugawa S, Yamazaki Y, Sugano E, Nagakura Y, Yoshida K, Fukuchi K. SCCmec typing of PVL-positive community-acquired Staphylococcus aureus (CA-MRSA) at a Japanese hospital. Heliyon. 2019. 5: e01415.

Gill VC, Ma I, Guo M, Gregson DB, Naugler C, Church DL. Sociodemographic and geospatial associations with communityassociated methicillin-resistant Staphylococcus aureus (CAMRSA) infections in a large Canadian city: an 11 year retrospective study. BMC Public Health. 2019. 19: 914.

Hisata K, Ito T, Jin J, Li S, Watanabe S, Hiramatsu K, Matsunaga N, Komatsu M, Shimizu T. Dissemination of multiple MRSA clones among community-associated methicillin-resistant Staphylococcus aureus infections from Japanese children with impetigo. Journal of Infection and Chemotherapy. 2011. 17: 609-621.

Hong SB, Baek YH. Study on the Contamination of MethicillinResistant Staphylococcus (MRS) in a High School Environment. Korean Journal of Clinical Laboratory Science. 2017. 49: 420-426.
Jung YH, Kim HB. Multidrug-Resistant Gram-Positive Bacterial Infections. Korean Journal of Medicine. 2015. 88: 487-501.

Kang GS, Jung YH, Kim HS, Lee YS, Park C, Lee KJ, Cha JO. Prevalence of major methicillin-resistant Staphylococcus aureus clones in Korea between 2001 and 2008. Annals of Laboratory Medicine. 2016. 36: 536-541.

Kim ES, Kim HB, Kim G, Kim KH, Park KH, Lee S, Choi YH, Yi J, Kim CJ, Song K-H, Choe PG, Kim N-J, Lee Y-S, Oh M-D. Clinical and epidemiological factors associated with methicillin resistance in community-onset invasive Staphylococcus aureus infections: prospective multicenter cross-sectional study in Korea. Plos One. 2014. 9: e114127.

Kim H-S, Park S-B, Kim S-G, Kim SH, Hyun S-H, Kim Y-G. Molecular Genetic Characteristics of Methicillin-Resistant Staphylococcus aureus Isolated from Patients and Environment of General Hospital Intensive Care Unit in a Chungnam Province, Korea. Korean Journal of Clinical Laboratory Science. 2018. 50: 110-117.

Lakhundi S, Zhang K. Methicillin-resistant Staphylococcus aureus: molecular characterization, evolution, and epidemiology. Clinical Microbiology Reviews. 2018. 31: e00020-18

Leamer NK, Clemmons NS, Jordan NN, Pacha LA. Update: community-acquired methicillin-resistant Staphylococcus aureus skin and soft tissue infection surveillance among active duty military personnel at Fort Benning GA, 2008-2010. Military Medicine. 2013. 178: 914-920.

Miller LG, Diep BA. Colonization, fomites, and virulence: rethinking the pathogenesis of community-associated methicillinresistant Staphylococcus aureus infection. Clinical Infectious Diseases. 2008. 46: 752-760.

Ostojić M, Hukić M. Genotypic and phenotypic characteristics of Methicillin-resistant Staphylococcus aureus (MRSA) strains, isolated on three different geography locations. Bosnian Journal of Basic Medical Sciences. 2015. 15: 48.

Peng H, Liu D, Ma Y, Gao W. Comparison of community-and healthcare-associated methicillin-resistant Staphylococcus aureus isolates at a Chinese tertiary hospital, 2012-2017. Scientific Reports. 2018. 8: 1-8.

Petinaki E, Spiliopoulou I. Methicillin-resistant Staphylococcus aureus among companion and food-chain animals: impact of human contacts. Clinical Microbiology and Infection. 2012. 18: 626-634.

Shin H-S, Park Y-B. Isolation Frequency of Staphylococcus species from clinical materials. Korean J Clin Lab Sci. 2007. 39: 76 -85 . 
Sowash MG, Uhlemann AC. Community-associated methicillinresistant Staphylococcus aureus case studies. In: MethicillinResistant Staphylococcus aureus (MRSA) Protocols. Humana Press, Totowa, NJ, 2014. 1085: 25-69.

Suginaka H, Shimatani M, Ogawa M, Kotani S. Prevention of penicillin-induced lysis of Staphylococcus aureus by cellular lipoteichoic acid. The Journal of Antibiotics. 1979. 32: 73-77.

Xie X, Bao Y, Ouyang N, Dai X, Pan K, Chen B, Deng Y, Wu X, Xu F, Li H, Huang S. Molecular epidemiology and characteristic of virulence gene of community-acquired and hospitalacquired methicillin-resistant Staphylococcus aureus isolates in
Sun Yat-sen Memorial hospital, Guangzhou, Southern China. BMC Infectious Diseases. 2016. 16: 339.

https://doi.org/10.15616/BSL.2020.26.3.230

Cite this article as: Park H, Park SB, Kim J, Jeon H, Choi S, Lee S, Oh E, Hwang S, Kim H, Kim J, Kim S. Molecular Genetic Characteristics Methicillin-Resistant Staphylococcus aureus Isolated from University Campus Environment and Students. Biomedical Science Letters. 2020. 26: 230-237. 